\title{
The Influence of Oxygen on the Rate of Nitrogen Absorption into Molten Iron and Marangoni Convection
}

\author{
ZHU Jun and Kusuhiro MUKAI ${ }^{1)}$
}

Graduate Student, Department of Materials Science and Engineering, Faculty of Engineering, Kyushu Institute of Technology, Sensui-cho, Tobata-ku, Kitakyushu, Fukuoka-ken, 804-0015 Japan.

1) Department of Materials Science and Engineering, Faculty of Engineering, Kyushu Institute of Technology, Sensui-cho, Tobata-ku, Kitakyushu, Fukuoka-ken, 804-0015 Japan.

(Received on September 4, 1997; accepted in final form on November 4, 1997)

\begin{abstract}
Under the condition of non-induction stirring, the Marangoni convection that occurred in the process of nitrogen absorption into the liquid iron with various oxygen contents was investigated. Using the periscopic high temperature lens and $X$-ray radiography system, the surface velocity induced by the Marangoni effect due to the nitrogen absorption into liquid iron was observed and the surface velocity was measured. The surface velocity decreased with the increase of oxygen contents. In the present study, the rate of nitrogen absorption into liquid iron containing $20-500 \mathrm{ppm}$ oxygen could be described with a first order rate equation, and the process of nitrogen absorption is dominated by the mass transfer in the liquid iron. The apparent mass transfer coefficient was reduced with increasing oxygen concentration. This is mainly due to the dwindling of the Marangoni convection on the surface of liquid iron.
\end{abstract}

KEY WORDS: Marangoni convection; nitrogen absorption rate; rate determining step; non-induction stirring; oxygen concentration.

\section{Introduction}

It is well known that nitrogen significantly affects the mechanical properties of iron and steel. In order to control nitrogen content in the steel, it is important to understand the kinetics of the nitrogen reaction with liquid iron.

Since 1960 many investigators ${ }^{1-3)}$ have studied the kinetics of the nitrogen absorption and desorption in molten iron and its alloys. As a result, most of the researchers believe that in the case of low concentration of surface active solute elements, such as oxygen and sulfur, the rate of nitrogen absorption is mostly treated as a first order reaction with respect to the dissolved nitrogen, and the rate is supposed to be controlled by the rate of mass transfer in the liquid iron. On the other hand, for high concentration of surface active solute elements, the rate of nitrogen absorption is expressed by a second order rate equation with respect to nitrogen in the liquid iron, the rate controlling step being the chemical reaction at the gas-melt interface. There is also general agreement that surface-active elements such as oxygen, sulfur, etc., inhibit the absorption of nitrogen into molten iron. The mechanism that surface-active elements affect on the reaction rate is explicated by a surface blocking model or surface poison model. ${ }^{4)}$ However, there is considerable uncertainty about the influence of flow condition in the liquid phase on the rate of the reaction at high contents of surface-active elements. Richardson ${ }^{5)}$ found that sulfur and oxygen were highly effective in retarding the process of nitrogen absorption into liquid iron and reported that the retarding effect changes for different ways of nitrogen absorption. With the same content of sulfur, the retarding effect on the nitrogen absorption by blowing nitrogen onto the surface of liquid iron, which was inductively stirred in a crucible, is five times bigger than nitrogen absorption by rising nitrogen gas bubbles into the liquid iron, and 3 times smaller than nitrogen absorption by free falling drops of iron through the nitrogen gas. Nonetheless, as several investigators reported, the chemical reaction at the gas-melt interface became rate-controlling step when the surface-active element concentration was high. So, the rate of nitrogen absorption must be a constant value if the surface-active element concentration is the same, regardless of stirring conditions. Namely there were some conflicts among the results. It is highly possible that flow conditions were different in the three sets of experiments, and this may be the principal cause of the different rate of nitrogen absorption. Fruehan and Martonic ${ }^{6)}$ discovered that the absorption reaction becomes second order, and the nitrogen absorption rate decreases with increasing surface active element oxygen and sulfur concentration. But, the reaction rate approaches a constant 'residual rate' at high levels of oxygen and sulfur. One plausible explanation of the residual rate is that the convection of the liquid phase still influences the nitrogen absorption rate although the chemical reaction becomes rate controlling step in this situation by them. 
Several researchers ${ }^{5,7,8)}$ pointed out the Marangoni effect, which is caused by surface or interfacial tension gradient, may promote mass transfer across the surface/ interface, and therefore, enhance the rate of reactions at high temperature metallurgical processes. Mukai et al. ${ }^{9)}$ directly observed the Marangoni effect in the gas-liquid, slag-solid oxide and melting metal-liquid slag-solid oxide systems, and concluded that the Marangoni convection plays an important role in the local corrosion of refractory at the gas-slag and metal-slag interface. In recent years, a lot of research ${ }^{10,11)}$ has been conducted to observe the high speed flow and turbulence on the gas-metal interface when surface-active element oxygen or reduction gas hydrogen was blown onto the surface of liquid metal. It was believed that the high-speed flow and turbulence occurred due to the Marangoni effect which is caused by oxygen concentration gradients. However, the relation between Marangoni convection and mass-transfer coefficient was not well examined.

Recently, Hirashima ${ }^{12)}$ et al. investigated the effect of the Marangoni convection on the rate of nitrogen absorption into liquid iron by using a resistance furnace Marangoni convection due to surface tension gradients, set up in a nitrogen-liquid iron system at $1873 \mathrm{~K}$, was mathematically simulated and experimentally confirmed by measuring the rate of nitrogen absorption into liquid iron and by observing the free surface motion of liquid iron by X-ray radiography. The results show that Marangoni convection in this system is mildly turbulent, and the Marangoni convection increased the mass transfer coefficient of nitrogen into liquid iron by one order of magnitude as compared to that due to diffusion alone. However, these results just reveal the mechanism of the reaction between the nitrogen and liquid iron containing lower oxygen content. In almost all cases of iron and steel making processes, reactions are accompanied by oxygen which is one of the strong surface agents for liquid iron, so that the Marangoni convection may participate more or less in various processes. As mentioned above, oxygen significantly inhibits the absorption of nitrogen into molten iron. It is possible that oxygen changes the rate of nitrogen absorption into the liquid iron by affecting the Marangoni convection due to nitrogen concentration gradients on the surface of liquid iron. Such consideration may reveal additional phenomena like, why and how the liquid phase mass transfer affects the nitrogen absorption with different oxygen contents. Moreover, the rate constant of nitrogen absorption adopted by most of investigators was obtained without considering the influence of the Marangoni convection in the liquid iron, especially at the high concentration of surface-active element. It is significant to investigate the relation between the rate of nitrogen absorption and flow conditions in the liquid iron. In turn, this investigation will help deeper understanding of the mechanism of gas-metal reaction in practical iron and steel making.

In the present work, first, the free surface motion was observed when nitrogen was blown onto the surface of liquid iron with various oxygen concentrations, and the motion speed was measured. At the same time, the rate

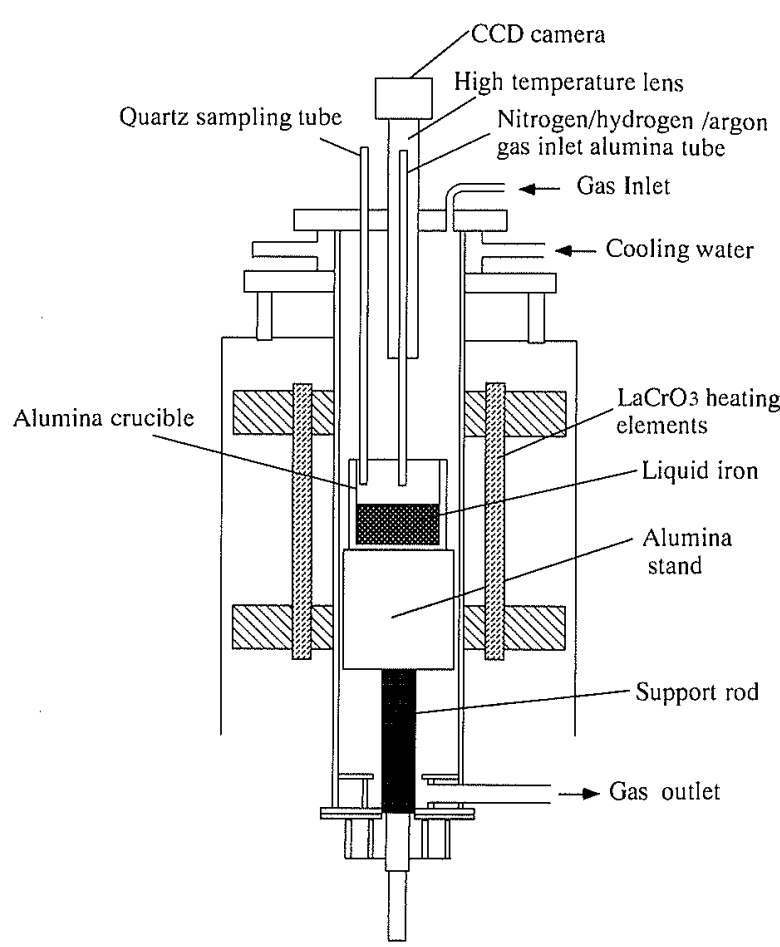

Fig. 1. Scheme of experimental apparatus.

of nitrogen absorption into $\mathrm{Fe}-\mathrm{O}$ alloy was measured by the sampling method. Then, the relation between the oxygen concentration and the Marangoni convection due to nitrogen concentration gradients on the surface of liquid iron, and the relation between the surface motion velocity, oxygen concentration, and rate of nitrogen absorption into molten iron were examined. To avoid the effect of inductive stirring in the liquid iron, the resistance furnace was selected, and all experiments were carried out at $1823 \mathrm{~K}$.

\section{Experimental}

\subsection{Apparatus}

The experimental set-up consisted of a heating and reaction section, an observation system and a gas purification system.

The heating and reaction section of the apparatus is shown in greater detail in Fig. 1. The resistance furnace was heated by $\mathrm{LaCrO}_{3}$ heating elements. A high-purity alumina $\left(99.8 \% \mathrm{Al}_{2} \mathrm{O}_{3}\right.$ ) round crucible ( $50 \mathrm{~mm}$ in O.D., $40 \mathrm{~mm}$ in I.D., $65 \mathrm{~mm}$ in height) which contained electrolytic iron was set in the alumina reaction tube $(70 \mathrm{~mm}$ in O.D., $60 \mathrm{~mm}$ in I.D., $700 \mathrm{~mm}$ in length) with two water cooled stainless caps. The gases were allowed to flow in the experiment and were blown onto the surface of liquid iron through a gas lance, which was a $3 \mathrm{~mm}$ I.D. highpurity alumina tube. The lance was placed just above the center of the crucible. The distance between the tip of the lance and the surface of liquid iron was $35 \mathrm{~mm}$. The gas outlet was on the bottom of the reaction tube. The quartz tube (I.D. in $4 \mathrm{~mm}$ ) which was held firmly by an adjustable clamp with an O-ring seal was used for taking the sample of liquid iron.

As shown in Fig. 2, the observation system consisted of high temperature X-ray radiographic apparatus and 


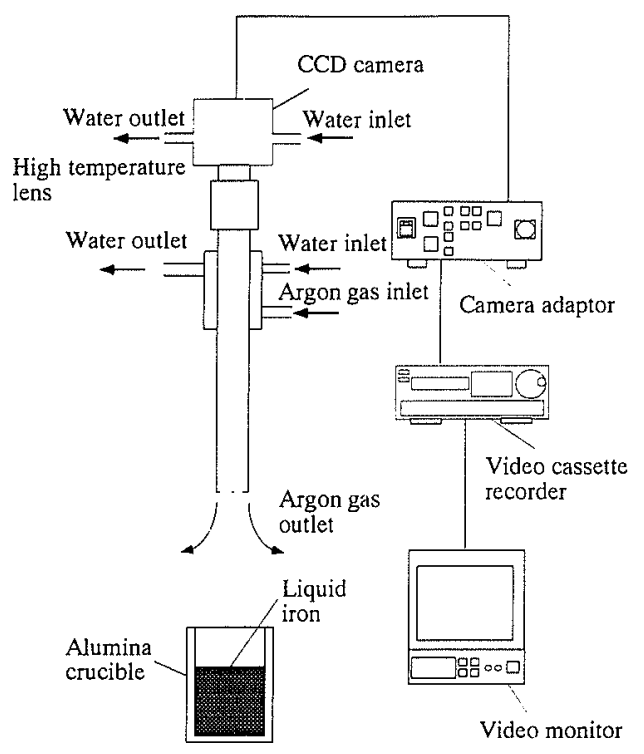

(a) High temperature lens apparatus.

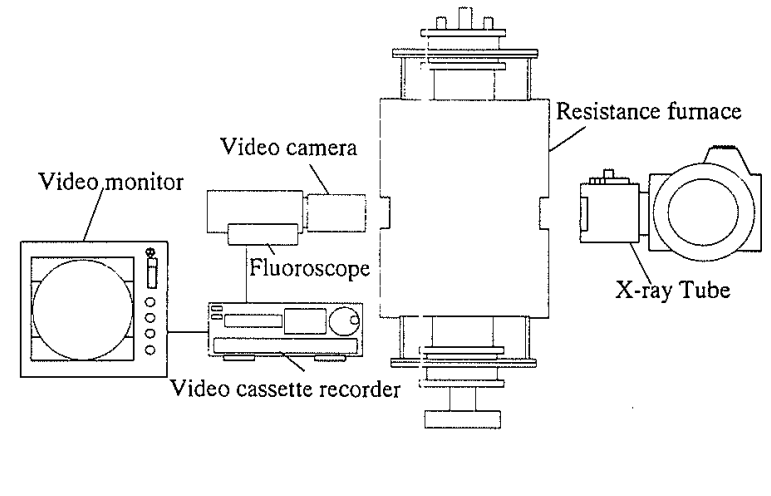

(b) High temperature X-ray radiographic apparatus.

Fig. 2. Schematic diagram of liquid iron surface flow observation systems.

periscopic high temperature lens apparatus. The X-ray apparatus was used to observe the surface movements of liquid iron via an inert mark from a lateral direction, and to adjust the position of gas lance over the surface of liquid iron. The image was recorded by a videocassette recorder that was connected to a video monitor. However, the motion of the mark may not be parallel with the surface perpendicular to the X-ray fluoroscope. Thus, the motion distance, which was observed by X-ray fluoroscopy, may not be accurate.

In this experiment, besides X-ray radiographic apparatus, the periscopic high temperature lens was adopted. The high temperature lens, which is fitted with a gas and water cooling system, can be used at $1273 \mathrm{~K}$. As the lens was fixed directly above the surface of liquid iron in the reaction tube, the appearance of the surface and the motion of the marks could be viewed clearly. The high temperature lens was attached to a 3-CCD color camera and the signal was transferred to a high-resolution monitor and received by a videocassette recorder. The motion of the liquid iron surface can be observed and recorded from both a horizontal and a vertical direction.

The gas purification system consists of high purity argon $\left(\mathrm{O}_{2}<0.2 \mathrm{ppm}\right)$, nitrogen $\left(\mathrm{O}_{2}<0.2 \mathrm{ppm}\right)$ and hydrogen. The argon and nitrogen gases were passed through the columns of Ascarite and $\mathrm{P}_{2} \mathrm{O}_{5}$ to remove the $\mathrm{CO}_{2}$ and moisture. The gases were further deoxidized by copper nets heated at $873 \mathrm{~K}$ and were then introduced into the reaction tube.

\subsection{Procedure}

The $200 \mathrm{~g}$ electrolytic iron, which was polished and rinsed with ethanol, was melted under argon atmosphere $(500 \mathrm{~m} / / \mathrm{min})$ in the alumina crucible at $1823 \mathrm{~K}$. The chemical analysis of electrolytic iron is shown in Table $\mathbf{1 .}$

For high purity iron, the oxygen dissolved in the liquid iron was removed by blowing the hydrogen $(500 \mathrm{~m} / / \mathrm{min})$ onto the surface of liquid iron for $30 \mathrm{~min}$, and then argon
Table 1. Chemical analysis of electrolytic iron. (ppm)

\begin{tabular}{lcccccccc}
\hline Element & $\mathrm{C}$ & $\mathrm{S}$ & $\mathrm{P}$ & $\mathrm{Si}$ & $\mathrm{Mn}$ & $\mathrm{Cu}$ & $\mathrm{N}$ & $\mathrm{O}$ \\
\hline Composition & 12 & 5 & $<10$ & $<5$ & $<1$ & 1 & 2 & 60 \\
\hline
\end{tabular}

$(1000 \mathrm{~m} / / \mathrm{min})$ was introduced for another $30 \mathrm{~min}$ before changing to nitrogen $(1000 \mathrm{~m} / / \mathrm{min})$. The oxygen concentration can be controlled at around 20-30 ppm. For $\mathrm{Fe}-\mathrm{O}$ alloy, the oxygen content was adjusted by adding high purity $\mathrm{Fe}_{2} \mathrm{O}_{3}$.

Then, the purified nitrogen gas was introduced by the gas lance onto the surface of liquid iron, and the flow rate of nitrogen gas was $1000 \mathrm{~m} / / \mathrm{min}$. The flow rate, $1000 \mathrm{~m} / / \mathrm{min}$, was adopted by a preliminary experiment, in which the rate of nitrogen absorption into the liquid iron containing lower surface-active elements was measured with different nitrogen flow rates, with the lance height of $35 \mathrm{~mm}$. It has been found that the rate of nitrogen absorption is first order (see Fig.7 (a), which will be described later) with respect to the nitrogen content in the liquid iron containing low surface-active elements. ${ }^{1-6)}$ Accordingly, the rate of nitrogen absorption into the liquid iron can be described with apparent mass transfer coefficient. Figure 3 illustrates the results that show the apparent mass transfer coefficient increased when the nitrogen flow rate was raised from 300 to $1000 \mathrm{~m} / / \mathrm{min}$. When the nitrogen flow rate was over $1000 \mathrm{ml} / \mathrm{min}$, the apparent mass transfer coefficient became almost constant. Therefore, it may be deduced that a nitrogen flow rate of $1000 \mathrm{~m} / / \mathrm{min}$ or more is sufficient to neglect the resistance of mass transfer in the gas phase at the nitrogen absorption in this experimental system. The purpose of the present study is to investigate the effect of the surface flow of liquid iron on the rate of nitrogen absorption, so that it is necessary to minimize the mass transfer resistance and the gas flow drag 


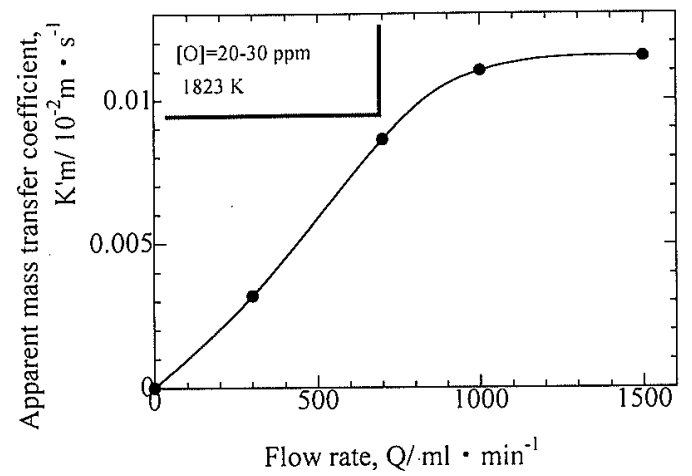

Fig. 3. Relation between flow rate and apparent mass transfer coefficient.

momentum on the surface motion. Thus, $1000 \mathrm{ml} / \mathrm{min}$ was selected as the flow rate of nitrogen in the experiment. In the present study, the argon gas was introduced into the reaction tube at the flow rate of $500 \mathrm{~m} / / \mathrm{min}$ from the tip of the lens as shown in Fig. 2(a), while nitrogen gas was blown onto the surface of liquid iron. Thus, the average partial pressure of nitrogen was kept at $0.67 \mathrm{~atm}$ in the reaction tube. There are two purposes for Ar gas supply. The first is to protect the high temperature lens. The second is to keep a difference in the partial pressure of nitrogen on the surface of the liquid iron when the reaction is into a steady state, which is necessary to promote the Marangoni convection. At the beginning of the blowing of nitrogen gas onto the center of the liquid iron, there was a big difference in nitrogen partial pressure between the center of the crucible and its wall. Since the resistance of mass transfer in the gas phase becomes very small when the nitrogen gas flow rate exceeds 1000 $\mathrm{m} / / \mathrm{min}$, the nitrogen partial pressure in the vicinity of nitrogen impinged area could be maintained near $1 \mathrm{~atm}$. At the same time, the nitrogen partial pressure is near zero in the wall of crucible. Along with the nitrogen absorption into the liquid iron, the nitrogen concentration in the liquid iron is increased and the gradient of nitrogen concentration on the liquid iron surface decreases. However, when the nitrogen partial pressure was kept at $0.67 \mathrm{~atm}$ in the reaction tube, the difference in the partial pressure of nitrogen on the surface of the liquid iron could be maintained. There is an exception in the experiment of determining the rate-controlling step of the nitrogen absorption into the molten iron in the present study. The experiment was carried out by measuring the rate of nitrogen absorption with various nitrogen partial pressures. Three different nitrogen pressure were used: $0.3,0.67$ and $1.0 \mathrm{~atm}$. The partial pressure of nitrogen was controlled by using nitrogenargon gas mixture, and the total pressure and flow rate were held constant at 1 atm and $1000 \mathrm{~m} l /$ min respectively. In order to control the nitrogen partial pressure conveniently and to obtain $P_{\mathrm{N}_{2}}=1.0 \mathrm{~atm}$, it is better not set the periscopic high temperature lens into reaction tube as the $500 \mathrm{ml} / \mathrm{min}$ argon gas had to flow around the head of lens for protecting the lens. So, the gas mixtures with various nitrogen partial pressures were blown onto the surface of liquid iron directly.

Since it was impossible to observe a surface motion of liquid iron directly due to the brilliance of liquid surface at high temperature, the small zirconium oxide particles (1-2 mm in diameter) were used as markers which were laid on the surface of liquid iron through the gas lance. The motion of the markers was observed using the periscopic high temperature lens and X-ray fluoroscope and recorded on videotape. The velocity was calculated based on the marker's position frame by frame.

The rate of nitrogen absorption into liquid iron was measured by determining the nitrogen content in the molten metal, using the sampling method. After nitrogen was allowed to flow onto the surface of liquid iron, the suction samples were taken from the molten metal with a quartz tube at 1 or 2-min intervals, and were quenched in water. Nitrogen and oxygen contents were analyzed by an oxygen and nitrogen determinator of infrared rays absorption method with an accuracy of $\pm 2 \mathrm{ppm}$.

\section{Results and Discussion}

\subsection{Surface Motion}

Observing with the X-ray fluoroscope, the contour of liquid iron surface appeared to be convex, due to the non-wetting behavior of the liquid iron on the wall of the alumina crucible. It is very difficult to place the $\mathrm{ZrO}_{2}$ particles in the center of liquid iron surface. In the present study, the $\mathrm{ZrO}_{2}$ particles were laid on the surface of molten iron through the alumina gas lance, while the nitrogen gas was blowing onto the surface of the liquid iron. Initially, the particles were dropped down to the surface of molten iron after 30-50 s of nitrogen blowing, and then the particles were dropped down for 2-min intervals. At each time about 2 or 3 particles were dropped down. The duration of each test is $6-8 \mathrm{~min}$ long. During experiment, the measured velocity was almost constant, but decreased less than $5 \%$ with a lapse of time. The velocity, which was measured after markers were dropped dawn (after 30-50s of nitrogen blowing), was adopted in the study. Since the distance from the top of the gas lance to the surface of the liquid iron is about $1 \mathrm{~m}$, the falling momentum of the markers, slope of the surface and momentum transfer from the gas jet might have caused the markers to move from the center of the liquid iron to the wall of the crucible. It is necessary to examine the effect of the driving force on the motion of the markers. Therefore, the motion of the markers on the surface of the liquid iron was observed under three different experimental conditions. The first test was conducted in an argon gas atmosphere, in which the argon gas was led into the reaction tube from the gas inlet of the high temperature lens at a flow rate of $500 \mathrm{ml} / \mathrm{min}$ as shown in Fig. 2(a). There was no direct gas blowing onto the surface of liquid iron. The second test was that argon gas was conducted onto the surface of liquid iron with a flow rate of $1000 \mathrm{ml} / \mathrm{min}$ which is in the same way and at the same flow rate as the third test. The third test was blowing the nitrogen gas onto the surface of liquid iron at a flow rate of $1000 \mathrm{ml} / \mathrm{min}$.

Figure 4 illustrates the observation of the surface motion. Under the condition of lower oxygen contents, when the markers reached the surface of the liquid iron 


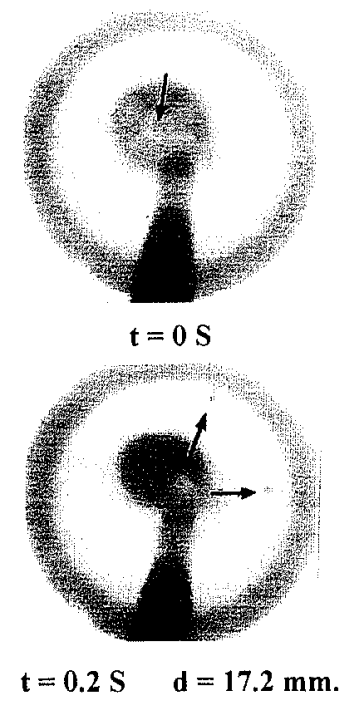

Fig. 4. Motion of markers on the liquid iron surface under the condition of nitrogen blowing.

[O]: $29.4 \mathrm{ppm}, V_{\mathrm{s}}: 0.0862 \mathrm{~m} / \mathrm{s}$. $d:$ Motion distance of markers, $\mathrm{mm} ; t$ : Motion time, s.

onto which the nitrogen gas was blown, the markers moved from the center to the wall of the crucible at a high speed. The average velocity of the markers was about $0.08-0.12 \mathrm{~m} / \mathrm{s}$. The value is consistent with the value of $0.05-0.11 \mathrm{~m} / \mathrm{s}$ obtained by Hirashima ${ }^{12)}$ et al. In the case of argon gas atmosphere and blowing argon gas, the motion of the markers from the center of the crucible to its wall was also observed. However, the motion velocity was much smaller than that of blowing nitrogen gas. In the argon atmosphere, without gas blowing, the velocity of the markers was about 0.01 $0.02 \mathrm{~m} / \mathrm{s}$. Blowing argon gas onto the surface of liquid iron, the velocity was about $0.01-0.025 \mathrm{~m} / \mathrm{s}$. Consequently, in the case of blowing nitrogen, the velocity of markers was the fastest among the three tests. It could be deduced that the difference in the motion velocity of the markers between blowing nitrogen and blowing argon gas was due to the different surface flow velocity, which was caused by the surface tension gradient on the surface of the liquid iron.

As shown in Fig. 5, when nitrogen was blown onto the surface of the liquid iron, the nitrogen concentration of the area directly below the gas lance was higher than that of the region near the wall of crucible. As nitrogen is a surface active element, the surface tension of the liquid iron in the vicinity of the nitrogen impinged area was lower than the surrounding area, and accordingly, the surface tension gradient was generated and the Marangoni convection occurred from the center to the surrounding of the crucible. However, argon gas is not a surface-active element to the liquid iron, so the surface flow of the liquid iron could only be induced by momentum of the gas gained from the gas jet, and not by the Marangoni convection. There is an interesting phenomenon when the nitrogen was blown onto the surface of liquid iron containing oxygen over $150 \mathrm{ppm}$. At the beginning when the markers reached the surface of the liquid iron onto which the nitrogen gas was blown,

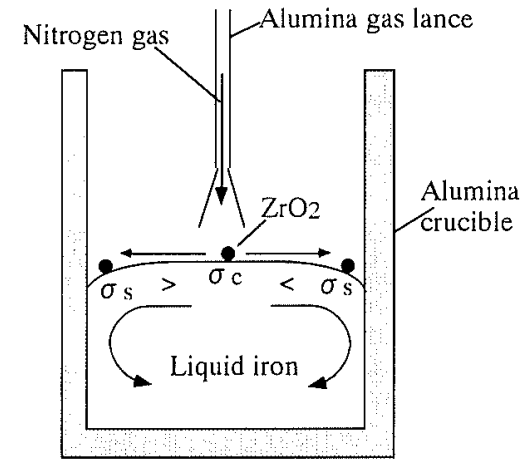

Fig. 5. Marangoni convection induced by nitrogen blowing on the surface of liquid iron.

$\sigma_{\mathrm{c}}$ and $\sigma_{\mathrm{s}}$ : Surface tension of the liquid iron in the center and surrounding of alumina crucible, respectively.

the markers moved from the center to the wall of the crucible. After 10-20 s, the markers returned to the center of crucible with a velocity about $0.055-0.075 \mathrm{~m} / \mathrm{s}$, the markers rotated on the surface of liquid iron about 40-60 s. Then the markers returned to the wall of crucible again. If new markers were dropped down the surface of liquid iron subsequently, the phenomenon would not occur again, the markers just moved from the center to the wall of crucible. The mechanism of the phenomenon is not very clear yet. This may be a characteristic phenomenon of nonlinear dynamics induced by the Marangoni effect at the initial stage of nitrogen blowing onto liquid iron due to the introduction of surface active element, oxygen, into the $\mathrm{Fe}-\mathrm{N}$ system. As the velocity that the markers returned to the center of crucible approximately equals to the one that is from center to the wall of crucible, and the phenomenon only occurred in the initial stage of nitrogen absorption reaction, the effect of the phenomenon on the rate of nitrogen absorption would be smaller to the whole reaction process. So, the effect of the phenomenon could be left out in the present study.

Figure 6 shows the relation between the velocity of the markers and oxygen concentrations as nitrogen gas was blown onto the surface of liquid iron. When the oxygen concentration was altered from the 20 to $500 \mathrm{ppm}$, the velocity of the markers changed from $0.08-0.12$ to $0.045-0.055 \mathrm{~m} / \mathrm{s}$. This means that the velocity of the markers decreased as the oxygen concentration increased. The velocity of markers on the surface of the liquid iron by blowing argon gas and in the argon atmosphere was also shown in the Fig. 6. In both cases, the velocity of the markers was maintained at about $0.01-0.025 \mathrm{~m} / \mathrm{s}$ with the various oxygen concentrations. As the oxygen concentration was raised, the velocity of the marker declined very slightly. The behavior may have been brought about by the slope of the liquid iron surface becoming smaller, since the wettability between the liquid iron and the $\mathrm{Al}_{2} \mathrm{O}_{3}$ crucible will improve with increasing oxygen concentration. In the case of blowing the nitrogen, the Marangoni convection occurred on the surface of liquid iron. However, as oxygen is a stronger surface-active element than nitrogen in the liquid iron, ${ }^{13}$ ) the surface tension gradient caused by blowing nitro- 


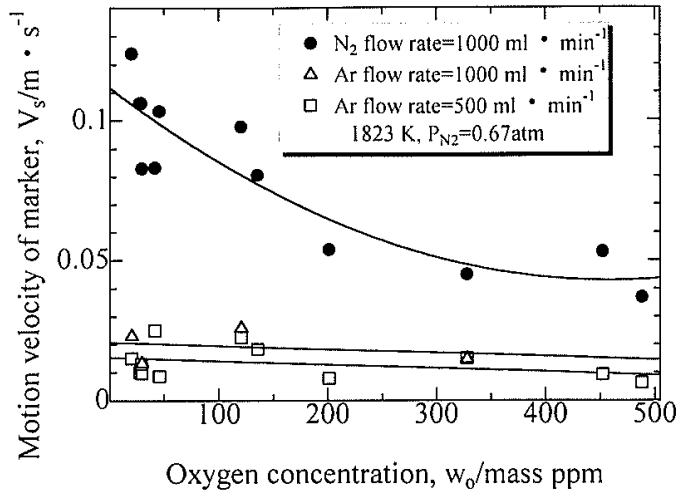

Fig. 6. Effect of oxygen concentration on motion velocity of markers.

gen onto the surface of liquid iron would be reduced. The surface flow velocity, which was induced by the Marangoni effect, would become slower as the oxygen concentration increased. Therefore, the velocity of the markers also decreased.

\subsection{Nitrogen Absorption Rate with Different Oxygen Concentrations}

3.2.1. Reaction Order and Rate Controlling Step

As discussed by many investigators, the process of nitrogen absorption into the liquid iron consists of the following three steps:

(1) Transfer of nitrogen molecules from the gas phase to the interface. (Gas phase mass transfer)

$$
\mathrm{N}_{2} \text { (gas) }=\mathrm{N}_{2} \text { (interface) }
$$

(2) Chemical reaction at the interface. (Adsorption/ dissociation)

$$
\mathrm{N}_{2} \text { (interface) }=2 \mathrm{~N}(\text { interface })
$$

(3) Transfer of nitrogen atoms from the interface to the bulk melt. ( Liquid phase mass transfer)

$$
\mathrm{N}(\text { interface })=\underline{\mathrm{N}}(\text { bulk })
$$

Among the three steps, the slowest step or several slower steps will control the overall rate of nitrogen absorption. It was mentioned above that the nitrogen flow rate was selected to be $1000 \mathrm{~m} / / \mathrm{min}$, which was sufficient to neglect the effect of mass transfer resistance in the gas phase on the process of the nitrogen absorption in the present study. It is acceptable not to consider the first step as rate limiting. Many researchers have reported that the rate of nitrogen absorption into liquid pure iron has a first order respect to the nitrogen concentration, and that the mass transfer in the liquid iron controls the rate. For high oxygen and sulfur content, the rate of nitrogen absorption could be expressed by a second order rate equation with respect to nitrogen concentration, and the rate controlling step being the chemical reaction at the gas-melt interface. However, since most of the investigations reviewed have utilized an inductionmelting system, which enhanced the stirring in the molten iron, the mass transfer in the bulk liquid was accelerated. For instance, the average velocity of liquid iron employed was found to be in the order of $0.2 \mathrm{~m} / \mathrm{s} .{ }^{1)}$ In the case of lower surface active elements, it might be easier for nitrogen molecules to adsorb and dissociate at the interface, thus the reaction rate was faster than the mass transfer in the liquid iron, hence, the mass transfer became the controlling rate step. On the other hand, when the surface-active element was higher, the chemical reaction rate was reduced ${ }^{14)}$ hence, the rate might be slower than the rate of mass transfer in the liquid iron that was accelerated by the induction agitation. In this case the chemical reaction on the interface could be determining the rate step. Under the condition of a resistance furnace, there is no electromagnetic turbulence in the liquid phase. The liquid iron would be stagnant and the mass transfer, which is controlled by diffusion and convection of the liquid iron at constant temperature, would be very weak compared with an induction furnace. Therefore, it may be deduced that the mass transfer in the liquid phase might become the rate controlling step in the process of nitrogen absorption into the liquid iron, regardless of whether the contents of surface active elements were high or low. At first, it is necessary to determine the rate-controlling step of the nitrogen absorption into the molten iron with a resistance furnace.

The rate of mass transfer in the liquid phase was represented by the following equation:

$$
\frac{d[\% \mathrm{~N}]_{t}}{d t}=K_{\mathrm{m}}^{\prime} \frac{A}{V}\left([\% \mathrm{~N}]^{\mathrm{i}}-[\% \mathrm{~N}]_{t}\right)
$$

where $K_{\mathrm{m}}^{\prime}$ : apparent mass transfer coefficient, $\mathrm{cm} \mathrm{s}^{-1}$,

$[\% \mathrm{~N}]^{\mathrm{i}}$ : equilibrium nitrogen concentration in the metal, mass \%,

$[\% \mathrm{~N}]_{t}:$ nitrogen concentration in the metal at time $t$, mass $\%$,

$A$ : reaction surface area of liquid iron, $\mathrm{cm}^{2}$,

$V$ : metal volume, $\mathrm{cm}^{3}$,

$t$ : reaction time, $\mathrm{s}$.

By integration of Eq. (1) the following relation is obtained:

$$
\ln \left\{\frac{[\% \mathrm{~N}]^{\mathrm{i}}-[\% \mathrm{~N}]_{0}}{[\% \mathrm{~N}]^{\mathrm{i}}-[\% \mathrm{~N}]_{t}}\right]=K_{\mathrm{m}}^{\prime} \frac{A}{V} t
$$

where $[\% \mathrm{~N}]_{0}$ : initial nitrogen concentration in the metal, mass $\%$.

The experimental results obtained at $1823 \mathrm{~K}$ with different oxygen concentrations are plotted in accordance with Eq. (2). The plots are given in Fig. 7. It is clearly seen that either at low oxygen concentration $([\mathrm{O}]=20$ $30 \mathrm{ppm}$ ) or at high oxygen concentration ([O] $=450$ $500 \mathrm{ppm}$ ) the first order plot according to Eq. (2) gives a single straight line regardless of nitrogen partial pressure. Hence, it is clear that the rate of nitrogen absorption is first order with respect to the nitrogen concentration of liquid iron in the case of the resistance furnace, not only at low contents of surface active elements which was accepted by all of investigators, but also at high contents of surface active elements. Therefore, the mass transfer in the liquid iron, controlled the rate of the nitrogen absorption into the liquid iron and could be described by a first order rate equation. 


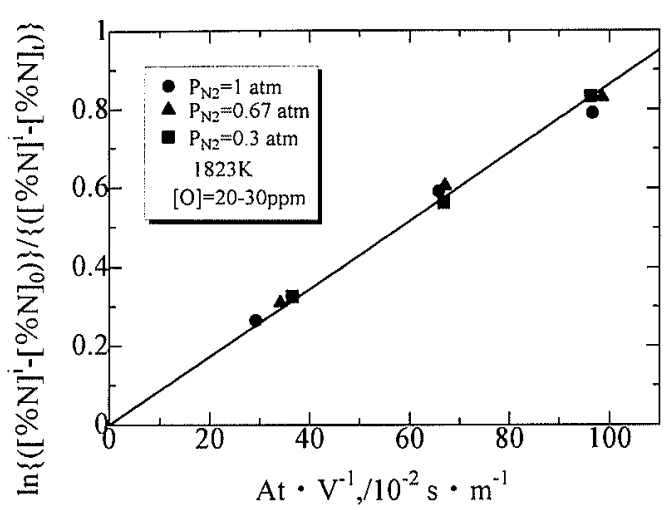

(a)

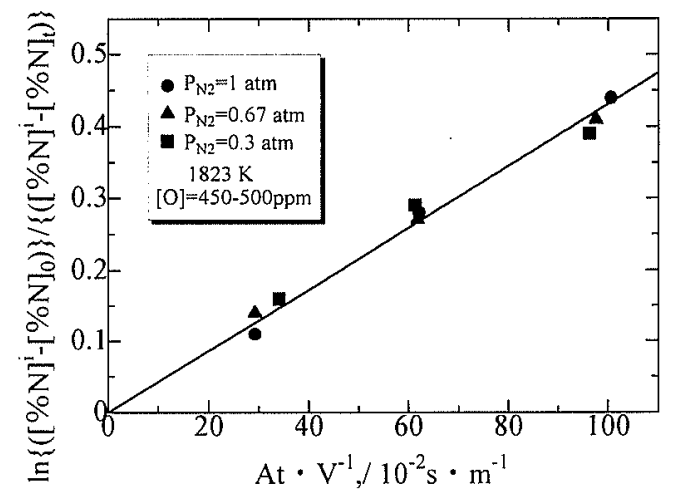

(b)

Fig. 7. Effect of nitrogen partial pressure on the relation between $\ln \left\{\left([\% \mathrm{~N}]^{\mathrm{i}}-\left[\% \mathrm{~N}_{0}\right)\right\} /\left\{\left([\% \mathrm{~N}]^{\mathrm{i}}-[\% \mathrm{~N}]_{t}\right)\right\}\right.$ and $A t \cdot V^{-1}$

\subsection{Effect of Oxygen on the Rate of Nitrogen Absorp- tion}

Figure 8 shows the plot of Eq. (2) using the experimentally measured nitrogen concentration with different oxygen contents. The slope of these straight lines gives the apparent mass transfer coefficient, $K_{\mathrm{m}}^{\prime}$. As the oxygen concentration increases, the apparent mass transfer coefficient, $K_{\mathrm{m}}^{\prime}$ becomes small. This means the rate of nitrogen absorption decreased with increasing oxygen concentration. The rate of mass transfer in the liquid phase is a function of the convection and diffusion rate. Mass transfer by convection is much more effective. As indicated above, Marangoni convection would occur when the nitrogen was blown onto the surface of liquid iron. The Marangoni convection would become weak as the oxygen concentration increased. Accordingly, it might be deduced that the change of the rate of nitrogen absorption into liquid iron with various oxygen contents was predominated by the status of Marangoni convection in the liquid iron. It could be found that the value of the apparent mass transfer coefficient in the Fig. 8 is a little bit larger than that in the Fig. 7(a) with the oxygen content of around $20-30 \mathrm{ppm}$. This may be deduced that as the experimental condition was different in the two situations, surface motion of the liquid iron was also different. This would lead to a change of the rate of nitrogen absorption into the liquid iron.

Figure 9 shows the relation between surface flow velocity of the liquid iron that was caused by the Marangoni effect and apparent mass transfer coefficient, $K_{\mathrm{m}}^{\prime}$. The

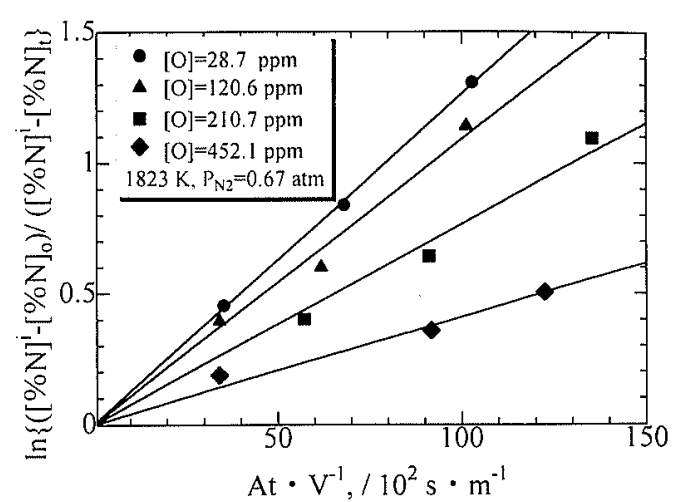

Fig. 8. Relation between $\ln \left\{\left([\% \mathrm{~N}]^{\mathrm{i}}-[\% \mathrm{~N}]_{0}\right)\right\} /\left\{\left([\% \mathrm{~N}]^{\mathrm{i}}-\right.\right.$ $\left.\left[\% \mathrm{~N}_{t}\right)\right\}$ and $A t \cdot V^{-1}$ with various oxygen concentrations.

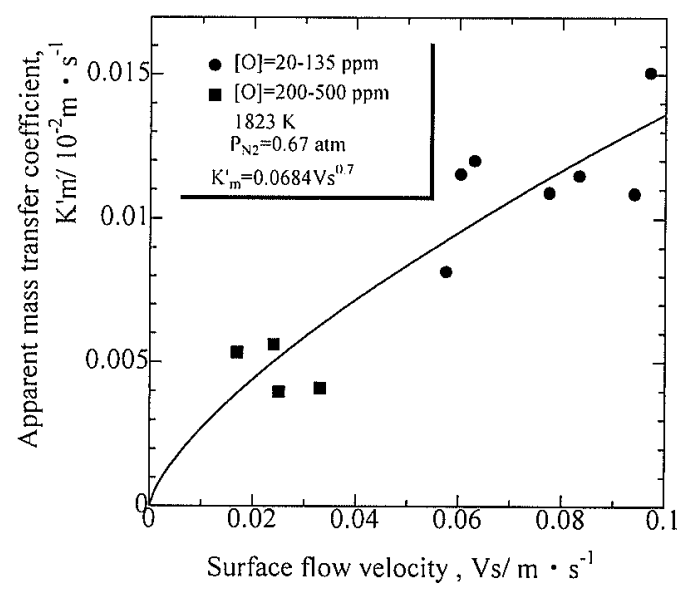

Fig. 9. Relation between surface flow velocity and apparent mass transfer coefficient.

surface flow rate was obtained by subtracting the motion velocity of markers in blowing argon gas from the one in blowing nitrogen gas. The apparent mass transfer coefficient was increased with the surface flow rate. Kikuchi et al. ${ }^{20)}$ proposed the dimensionless correlation for a mass transfer coefficient in the metal phase under a gas-metal reaction as follows:

$$
\mathrm{Sh}=\xi(\mathrm{Re} \cdot \mathrm{Sc})^{0.7}
$$

where

Sherwood number $\mathrm{Sh}=\frac{K_{\mathrm{m}}^{\prime} R}{D} ;$

Reynolds number $\operatorname{Re}=\frac{V_{\mathrm{s}} R}{v}$;

Schmidt number $\quad \mathrm{Sc}=\frac{v}{D}$;

$\xi$ is some constant, $v$ is kinematic viscosity, $D$ is diffusion coefficient, $R$ is radius of crucible and $V_{\mathrm{s}}$ is the surface flow velocity.

It means that the apparent mass transfer coefficient, $K_{\mathrm{m}}^{\prime}$ and surface flow velocity, $V_{\mathrm{s}}$ may have a 0.7 order relation. That is $K_{\mathrm{m}}^{\prime} \propto V_{\mathrm{s}}^{0.7}$. So the experimental dates were regressed and the following equation was obtained.

$$
K_{\mathrm{m}}^{\prime}=0.0684 V_{\mathrm{s}}^{0.7}
$$

The regression curve is shown in Fig. 9 and it reveals 
Table 2. Apparent mass transfer coefficients, $K_{\mathrm{m}}^{\prime}$ in high purity iron.

\begin{tabular}{|c|c|c|c|c|c|}
\hline Authors & $\begin{array}{l}\text { Oxygen concentration } \\
(\mathrm{ppm})\end{array}$ & $\begin{array}{c}\text { Temperature } \\
\text { (K) }\end{array}$ & Technique & $\begin{array}{l}\text { Surface velocity } \\
\qquad(\mathrm{m} / \mathrm{s})\end{array}$ & $\begin{array}{c}K_{\mathrm{m}}^{\prime} \\
\left(10^{-2} \mathrm{~m} / \mathrm{s}\right)\end{array}$ \\
\hline Present Work & $20-30$ & 1823 & ST/Resistance & $0.07-0.1$ & $0.01-0.015$ \\
\hline Hirashima et al. ${ }^{12)}$ & $76-100$ & I 873 & ST/Resistance & $0.05-0.11$ & 0.015 \\
\hline Choh et al. & $80-130$ & 1873 & ST/Induction & -0.2 & $0.027-0.035$ \\
\hline Pehlke et al. ${ }^{4\}}$ & 90 & 1873 & SI/Induction & not available & $0.021-0.032$ \\
\hline Lee et al. ${ }^{17)}$ & 20 & 1873 & Levitation & not available & 0.019 \\
\hline Glaws et $a l^{18)}$ & & 1873 & SI/Induction & not available & 0.022 \\
\hline Greenberg et al. ${ }^{19)}$ & 20 & 1873 & Levitation & not available & 0.031 \\
\hline
\end{tabular}

ST Sampling Technique; SI Sieverts cell

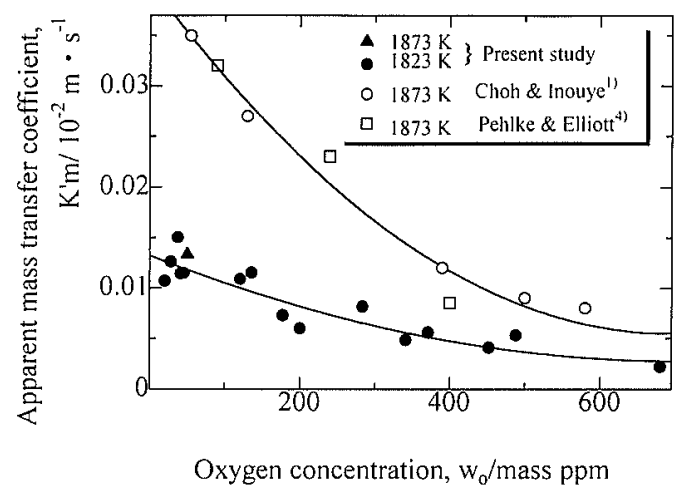

Fig. 10. Comparison of apparent mass transfer coefficients between present study and other investigators for nitrogen absorption into liquid iron with various oxygen concentrations.

the dependence of the apparent mass transfer coefficient on the Marangoni convection for nitrogen absorption into the liquid iron. The Marangoni convection enhanced the apparent mass transfer coefficient. When Marangoni convection declined with the oxygen increasing, the driving force to accelerate mass transfer in the liquid bulk was reduced, so the mass transfer coefficient was decreased.

\subsection{Comparison of the Nitrogen Absorption Rate with Inductive Stirring and Non-inductive Stirring}

Figure 10 shows the dependence of apparent mass transfer coefficient on the oxygen concentration. The results from other investigators are also included in this figure. The experimental condition for the present study was non-inductive stirring, and all literature values were obtained from inductive stirring. It is obvious from Fig. 10 that the apparent mass transfer coefficients for both situations are decreased as the oxygen concentration increased. The apparent mass transfer coefficient of other researchers was higher than that of this study.

However, the difference in apparent mass transfer coefficient between literature values and the present study was bigger in the case of lower oxygen concentration than that in the higher oxygen concentration. In general, inductive stirring is a fully developed turbulent condition and the average flow velocity of the liquid iron used for the study of nitrogen was reported to be over the order of $0.2 \mathrm{~m} / \mathrm{s} .{ }^{1)}$ In the present study, the surface flow velocity of liquid iron that was induced by Marangoni convection is about $0.07-0.1 \mathrm{~m} / \mathrm{s}$. With lower concentrations of oxygen, the mass transfer in the liquid iron became the rate-controlling step in both states. So, inductive stirring will accelerate the mass transfer rate faster than the Marangoni convection. It is reasonable that the difference in the apparent mass transfer coefficient between the two conditions is larger in the case of lower oxygen concentrations. Table 2 shows the apparent mass transfer coefficient obtained from the present study and from literature for high purity iron.

When the oxygen concentration is increased, the ratecontrolling step of the nitrogen absorption will be changed from mass transfer in the liquid bulk to the chemical reaction on the interface under the induction stirring condition. There will be less influence of the induction stirring on the reaction rate. Thus, it is expected that the difference in the apparent mass transfer coefficients of the two melting conditions becomes smaller.

\section{Conclusion}

(1) By blowing nitrogen onto the surface of liquid iron, the Marangoni convection caused by the surface tension gradient due to nitrogen concentration distribution was confirmed experimentally. The strength of the convection becomes weaker as the oxygen increases.

(2) Under the condition of non-induction stirring, the rate of nitrogen absorption into the liquid iron containing 20-500 ppm oxygen could be described with a first order rate equation, the process of nitrogen absorption being dominated by the mass transfer in the liquid bulk.

(3) The value of the apparent mass transfer coefficient was reduced with an increasing oxygen concentration. The relation between the apparent mass transfer coefficient and surface flow velocity caused by the Marangoni effect could be described with the equation, $K_{\mathrm{m}}^{\prime}=$ $0.0684 V_{\mathrm{s}}^{0.7}$. It could be deduced that the reduction of the apparent mass transfer coefficient mainly resulted from the dwindling of the Marangoni convection on the surface of liquid iron. The result indicates that the rate of nitrogen absorption obtained laboratorially using small masses of liquid iron includes the contribution of the Marangoni convection.

\section{REFERENCES}

1) T. Choh and M. Inouye: Tetsu-to-Hagane, 53 (1967), 1393.

2) Shimmyo and Takami: Proc. Int. Conf. Science \& Technology 
of Iron \& Steel, ISIJ, Tokyo, (1971), 538.

3) T. P. Battle and R. D. Pehlke: Ironmaking Steelmaking, 13 (1986), No. 4, 176.

4) R. D. Pehlke and J. F. Elliott: Trans. Metall. Soc. AIME, 227 (1963), 844.

5) F. D. Richardson: Can. Metall. Q., 21 (1982), 111.

6) R. J. Fruehan and L. J. Martonick: Metall. Trans. B, 12B (1981), 379.

7) M. Yamamoto and E. Kato: Tetsu-to-Hagané, 66 (1980), 608

8) K. W. Lange and M. Wilken: Can. Metall. Q., 22 (1983), 321.

9) K. Mukai: Materia Japan, 34 (1995), No. 4, 395.

10) J. K. Brimacombe and F. Weinberg: Metall.Trans., 3 (1972), 2298

11) R. G. Barton and J. K. Brimacombe: Metall. Trans., 8B (1977), 417.
12) N. Hirashima, R. T. C. Choo, J. M. Toguri and K. Mukai: Metall. Trans. B, 26B (1995), 971.

13) B. J. Keene: Int. Mater. Rev., 33 (1988), 1.

14) M. Byrne and G. R. Belton: Metall. Trans. B, 14B (1983), 441.

15) K. Saito: Youtetsu Yousai no Busseichi Binran, ISIJ, Tokyo, Japan, (1971), 347.

16) Y. Kawai: Tetu Yakin Hannou Sokudo Ron, Nikkan Kougyou Xinbenxia, (1973), 105.

17) Y. K. Rao and H. G. Lee: tronmaking Steelmaking, 12 (1985), No. 5, 209.

18) P. C. Glaw and R. J. Fruehan: Metall. Trans. B, 16B (1985), 551

19) L. A. Greenberg and A. Mclean: Ironmaking Steelmaking, 9 (1982), No. 2, 58

20) A. Kikuchi, S. Taniguchi, T. Tadaki and S. Maeda: Proc. Symp. Int. Union Theor. Mech., (1984), 79 